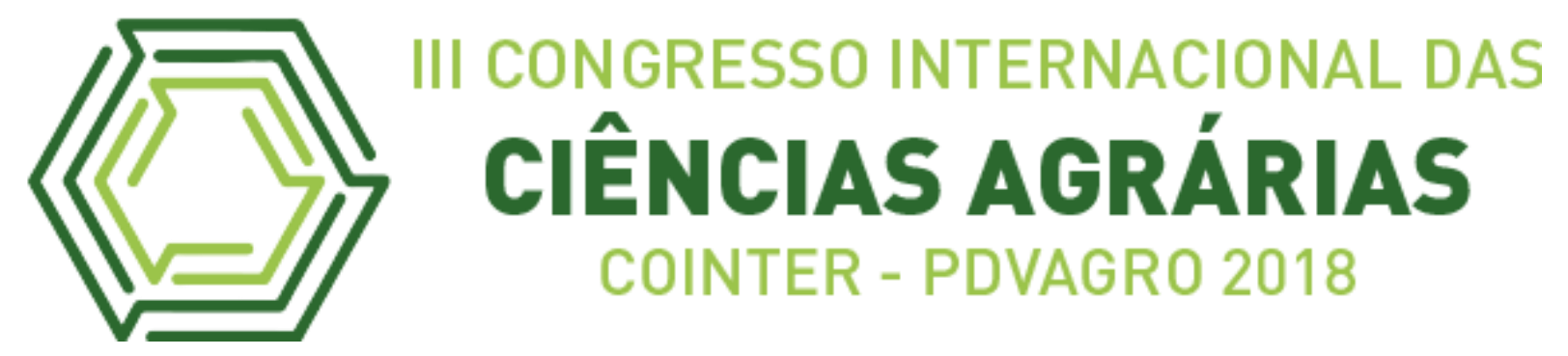

\title{
SUFICIÊNCIA AMOSTRAL DE INVENTÁRIO FLORESTAL NA AMAZÔNIA ATRAVÉS DO MÉTODO DE AMOSTRAGEM SISTEMÁTICA
}

\section{SAMPLE SUFFICIENCY FOR FOREST INVENTORY BY SYSTEMATIC SAMPLING METHOD IN THE AMAZON}

\author{
Apresentação: Pôster \\ Douglas Valente de Oliveira ${ }^{1}$; Laura Fernanda de Lima Lobato $^{2}$; Jobert Silva da Rocha ${ }^{3}$; \\ Bianca Diniz da Rocha ${ }^{4}$; Lia de Oliveira Melo ${ }^{5}$ \\ DOI: https://doi.org/10.31692/2526-7701.IIICOINTERPDVAGRO.2018.00666
}

\section{Introdução}

A Amazônia brasileira possui a maior extensão de floresta tropical do mundo, de acordo com estimativas do ano de 2015 do Sistema Nacional de Informações Florestais, o Brasil possui 94.639 milhões de metros cúbicos de madeira de florestas nativas, sendo que somente a Amazônia detém de $89 \%$ deste total com 84.616 milhões de metros cúbicos. Além da importância do ponto de vista do estoque de recursos madeireiros e não madeireiros, a floresta desempenha papel importante, tanto para servir de abrigo às diferentes formas de vida, como para manter o funcionamento equilibrado de seus ecossistemas (COLARES et al., 2010).

Neste sentido, o inventário florestal é o passo inicial para o planejamento da utilização racional do recurso através do manejo florestal, sendo que três tipos de inventário devem ser considerados: o inventário por amostragem, para uma avaliação do potencial da floresta; o inventário pré-exploratório, para o conhecimento detalhado dos blocos de exploração anual; e o inventário florestal contínuo, para monitorar o desenvolvimento da floresta, principalmente em termos de crescimento, ingressos e mortalidade (SILVA et al., 1985).

\footnotetext{
${ }^{1}$ Engenharia Florestal, Universidade Federal do Oeste do Pará, douglasvalenteoliveira@hotmail.com

2 Engenharia Florestal, Universidade Federal do Oeste do Pará, laura.fll@hotmail.com

${ }^{3}$ Engenharia Florestal, Universidade Federal do Oeste do Pará, jobert.job.rocha@gmail.com

${ }^{4}$ Engenharia Florestal, Universidade Federal do Oeste do Pará, Bianca_dinizdarocha@hotmail.com

${ }^{5}$ Doutora em Ciência Florestal, Universidade Federal do Oeste do Pará, Icolivei@gmail.com
} 
Dentro deste contexto, este trabalho teve como objetivo avaliar a suficiência amostral de inventário florestal por métodos estatísticos através dos dados obtidos, considerando três estratos da floresta, visando a redução de tempo e custos no manejo florestal.

\section{Fundamentação Teórica}

O inventário florestal é a base do plano de manejo e da produção de uma empresa madeireira. Este deve fornecer, além do volume total explorável, a distribuição do número de árvores por hectare e por classe de diâmetro; área basal por hectare, por classe de diâmetro, por grupo de espécies e para cada espécie individualmente (SILVA, 2001) o que torna possível prever gastos e lucros para a indústria madeireira.

A amostragem sistemática é um dos processos de amostragem probabilístico não aleatório, onde o critério de probabilidade se estabelece através da aleatorização da primeira unidade amostral. Vários processos de amostragem tratam da forma de abordagem da população sobre o conjunto de unidades amostrais, divididos em aleatório, sistemático ou misto. Na amostragem sistemática, a seleção das amostras segue um esquema rígido de seleção, cobrindo toda a extensão da população (SOARES et al., 2006), e somente a primeira é selecionada aleatoriamente, a partir da qual todas as demais são automaticamente selecionadas e distribuídas na população em estudo.

A confiabilidade dos valores obtidos na amostragem é apresentada através da precisão e exatidão, proximidade do estimador ao valor real e grau de aproximação do valor estimado do verdadeiro, o que depende principalmente da variabilidade da população mensurada, do tamanho da amostra e da metodologia de amostragem empregada no inventário (SOARES et al., 2006).

\section{Metodologia}

O presente trabalho foi desenvolvido na Floresta Nacional do Tapajós - FLONA Tapajós, uma unidade de conservação, com área aproximada de 545 mil hectares abrangendo os municípios de Belterra, Aveiro, Rurópolis e Placas no oeste do Pará (ICMBio, 2018). A vegetação predominante da FLONA Tapajós é classificada como Floresta Ombrófila Densa (ESPIRÍTO-SANTO et al., 2005).

O estudo foi conduzido em uma área de floresta não explorada de 100 ha, localizada no km 117 da BR-163. Foram lançadas 36 parcelas de $20 \mathrm{~m}$ x $50 \mathrm{~m}$, através do método de amostragem sistemática com inícios aleatórios múltiplos. A distância entre as linhas e entre 
parcelas foi de $50 \mathrm{~m}$. A distância da primeira parcela e de cada linha em relação a linha base foi obtida por sorteio.

Os indivíduos foram mensurados de acordo com os níveis de inclusão correspondentes aos extratos florestais, sendo que no nível de inclusão 1, estão inseridos a população total (DAP $\geq 10,0 \mathrm{~cm})$, no nível de inclusão 2 os indivíduos da regeneração natural $(10,0 \mathrm{~cm} \leq$ DAP $<50,0 \mathrm{~cm}$ ), e no nível 3 estão os indivíduos com diâmetro apto a colheita (DAP $\geq 50$ $\mathrm{cm})$.

Foram analisadas para todos os extratos as variáveis: número de indivíduos por hectare $\left(\right.$ n.ha $\left.{ }^{-1}\right)$, área basal $\left(\mathrm{G}\left(\mathrm{m}^{2} \cdot \mathrm{ha}^{-1}\right)\right)$, e volume $\left(\mathrm{V}\left(\mathrm{m}^{3} \cdot \mathrm{ha}^{-1}\right)\right.$ a $95 \%$ de probabilidade e precisão requerida de $10 \%$.

Para a análise estatística foram calculadas as variáveis: Média, Variância, Desvio Padrão, Coeficiente de Variação (CV\%), Variância da Média, Erro Padrão, Erro de Amostragem (E\%), Limite Superior, Limite Inferior e Dimensionamento.

\section{Resultados e Discussões}

A partir dos dados processados foi possível realizar análises estatísticas de abundância (n.ha $\left.{ }^{1}\right)$, área basal ( $\left.m^{2} . h a\right)$ e volume $\left(m^{3} . h a\right)$ em cada estrato, partindo disso, observa-se o diagnóstico estatístico do extrato regeneração referentes aos parâmetros amostrados no inventário (Tabela 1).

Tabela 1: Análise estatística da regeneração para as variáveis, número de arvores, área basal e volume considerando todas as árvores com $(10,0 \mathrm{~cm} \leq \mathrm{DAP}<50,0 \mathrm{~cm})$. Fonte: Própria

\begin{tabular}{cccc}
\hline Estatística & n.ha $^{\mathbf{1}}$ & $\mathrm{G}\left(\mathbf{m}^{\mathbf{2}} \mathbf{. h a}\right)$ & Vol. $^{\left(\mathbf{m}^{\mathbf{3}} \cdot \mathbf{h a}\right)}$ \\
\hline Média & 422,5 & 16,42 & 202,41 \\
$\mathrm{~S}^{2}$ & 28293,57 & 58,59 & 18202,84 \\
$\mathrm{~S}$ & 168,21 & 7,65 & 134,92 \\
$\mathrm{CV}$ & 39,81 & 46,61 & 66,65 \\
$\mathrm{SX}^{2}$ & 757,64 & 1,57 & 487,43 \\
$\mathrm{SX}$ & 27,53 & 1,25 & 22,08 \\
$\mathrm{E}$ & 55,88 & 2,54 & 44,82 \\
E\% & 13,23 & 15,48 & 22,14 \\
IC LI & 366,62 & 13,88 & 157,59 \\
IC LS & 478,38 & 18,97 & 247,24 \\
Dimensionamento & 61 & 97 & 155 \\
\hline
\end{tabular}


Observou-se o elevado grau de heterogeneidade no extrato considerado como regeneração natural, indicado pelo coeficiente de variação se encontra muito alto. A análise demonstrou que o número de parcelas alocadas não foi suficiente para atender a precisão de erro requerida de $10 \%$, para as três variáveis analisadas. Portanto, através do dimensionamento encontrou-se o número de parcelas necessárias para serem alocadas, representando 25, 46, 119 parcelas as variáveis, abundância $\left(\mathrm{n} \cdot \mathrm{ha}^{1}\right)$, área basal $\left(\mathrm{m}^{2} . h a\right)$ e volume $\left(\mathrm{m}^{3} \cdot \mathrm{ha}\right)$, respectivamente.

Gama et al. (2001) verificou que o tamanho ótimo de parcela para análise de regeneração natural foi de $70 \mathrm{~m}^{2}$ para os indivíduos na classe de tamanho 1 - CT1 $(0,3 \mathrm{~m} \leq \mathrm{h}<1,5 \mathrm{~m}) ; 80 \mathrm{~m}^{2}$ para a classe de tamanho 2 - CT2 $(\mathrm{h} \geq 1,5 \mathrm{~m}$ a DAP $<5 \mathrm{~cm})$ e $90 \mathrm{~m}^{2}$ para a classe de tamanho 3 - CT3 $(5 \mathrm{~cm} \leq \mathrm{DAP}<15 \mathrm{~cm})$, logo, um tamanho de parcela adequado pode influenciar diretamente nos resultados.

Para população dos indivíduos com DAP $\geq 50 \mathrm{~cm}$, as médias obtidas de número de indivíduos, área basal e volume foram 30,61 n.ha ${ }^{1}$, 14,47 m2.ha1 ${ }^{1}$ e 280,46 m³.ha respectivamente, o que representa uma floresta bem estocada em termos de volumetria de grandes árvores (Tabela 2).

Tabela 2: Análise estatística da população dos indivíduos comerciais para as variáveis, número de arvores, área basal e volume considerando todas as árvores com DAP $\geq 50 \mathrm{~cm}$. Fonte: Própria

\begin{tabular}{cccc}
\hline Estatística & $\mathbf{n . h a}^{\mathbf{1}}$ & $\mathbf{G}\left(\mathbf{m}^{\mathbf{2}} \cdot \mathbf{h a}\right)$ & Vol. $\left(\mathbf{m}^{\mathbf{3}} \cdot \mathbf{h a}\right)$ \\
\hline Média & 30,61 & 14,47 & 280,46 \\
$\mathrm{~S}^{2}$ & 293,37 & 73,23 & 30322,93 \\
$\mathrm{~S}$ & 17,13 & 8,56 & 174,13 \\
$\mathrm{CV}$ & 55,96 & 59,14 & 62,09 \\
$\mathrm{SX}^{2}$ & 8,6 & 2,15 & 888,55 \\
$\mathrm{SX}$ & 2,93 & 1,46 & 29,81 \\
$\mathrm{E}$ & 5,97 & 2,98 & 60,72 \\
E\% & 19,51 & 20,62 & 21,65 \\
IC LI & 24,63 & 11,49 & 219,74 \\
IC LS & 36,58 & 17,45 & 341,18 \\
Dimensionamento & 115 & 127 & 138 \\
\hline
\end{tabular}

As grandes árvores em florestas tropicais têm comumente distribuição bastante irregular o que pode ser verificado pelo elevado coeficiente de variação entre as parcelas, 
apresentando valores acima de 50\%. Devido a esta grande variabilidade os erros percentuais ficaram acima da precisão requerida de $10 \%$, permitindo verificar que o número de parcelas não foi suficiente para representar a população dentro do limite de erro aceitável. Através do dimensionamento foi possível verificar que são necessárias mais 82 parcelas para n.ha ${ }^{1}, 94$ para área basal e 105 para a variável volume.

Leão et al. (2018) obtiveram erro relativo para os volumes menores do que 10\%, que é o limite, sendo possível verificar que utilização de uma intensidade amostral de $15 \%$ foi considerada a melhor alternativa para avaliar Florestas Ombrófilas Abertas, pois apresentou erro amostral com menor número de parcelas a serem alocadas em campo, diminuindo, assim, os custos e tempo de operação do inventário florestal

Considerando a população total, as análises estatísticas demonstraram um menor erro percentual para as três variáveis analisadas em comparação com os outros extratos, porém também não foi possível atender a precisão requerida (Tabela 3).

Tabela 3: Análise estatística de toda população para as variáveis, número de arvores, área basal e volume considerando todas as árvores com DAP $\geq 10,0 \mathrm{~cm}$. Fonte: Própria

\begin{tabular}{cccc}
\hline Estatísticas & n.ha' $^{\mathbf{1}}$ & $\mathbf{G}\left(\mathbf{m}^{\mathbf{2}} \cdot \mathbf{h a}\right)$ & Vol. $\left(\mathbf{m}^{\mathbf{3}} \cdot \mathbf{h a}\right)$ \\
\hline Média & 450,56 & 29,69 & 459,5 \\
$\mathrm{~S}^{\mathbf{2}}$ & 28319,68 & 114,07 & 39764,43 \\
$\mathrm{~S}$ & 168,28 & 10,68 & 199,41 \\
$\mathrm{CV}$ & 37,35 & 35,98 & 43,4 \\
$\mathrm{SX}$ & 758,34 & 3,05 & 1064,8 \\
$\mathrm{SX}$ & 27,54 & 1,75 & 32,63 \\
$\mathrm{E}$ & 55,9 & 3,55 & 66,24 \\
E\% & 12,41 & 11,95 & 14,42 \\
IC LI & 394,65 & 26,14 & 393,26 \\
IC LS & 506,46 & 33,24 & 525,75 \\
Dimensionamento & 54 & 51 & 72 \\
\hline
\end{tabular}

Como o erro percentual está acima do limite, o dimensionamento mostra que são necessárias à instalação de mais parcelas para representar a população total e atender a precisão requerida.

Apesar do erro está acima do limite, é possível verificar um grande potencial madeireiro da área com 459,50 ( $\mathrm{m}^{3}$.ha). Higuchi (1987) verificou que a amostragem 
sistemática é mais precisa que a amostragem aleatória, quando se tem o objetivo de realizar inventários florestais por amostragem.

\section{Conclusões}

A floresta apresenta-se bastante heterogênea em relação a distribuição dos indivíduos arbóreos. A quantidade de parcelas alocadas na área não foi suficiente para a precisão requerida, nas três variáveis analisadas em todos os extratos, logo, nenhuma das variáveis obteve suficiência amostral, sendo necessário redimensionamento do número de parcelas e o retorno ao campo para complementar a amostragem.

\section{Referências}

COLARES, A. C. B.; MELO, L. O.; RIBEIRO, R. B. S. Inventário florestal diagnóstico do conjunto de glebas estaduais Mamuru Arapiuns - Pará. SEAT Terraplanagem Ltda., Manejo Florestal e prestação de serviços, Santarém, 2010.

LEÃO, F. M.; SILVA, L. F. D.; SOUSA, L. C. M.; MENEZES, M. C.; OLIVEIRA, M. H. S.; Neves, R. L. P.. Sample intensity in ombrophilous open forest at Verde Para Sempre Extractive Reserve, Porto de Moz, PA. Revista Agro@mbiente, Boa Vista v. 12, n. 1, p. 6879, 2017.

ESPIRITO-SANTO, F. D. B.; SHIMABUKURO, Y. E.; OLIVEIRA, L. E.; ARAGÃO, C.; MACHADO, E. L. M. Análise da composição florística e fitossociológica da floresta nacional do Tapajós com o apoio geográfico de imagens de satélites. Acta Amazônica, Manaus, v. 35, n. 2, p. 155-173, 2005.

GAMA, J. R. V.; BOTELHO, S. A.; BENTES-GAMA, M. M.; SCOLFORO, J. R. S. Tamanho de parcela e suficiência amostral para estudo da regeneração natural em floresta de várzea na Amazônia. Cerne, Lavras, v. 7, n. 2, p.1-11, 2001.

HIGUCHI, N. Amostragem sistemática versus amostragem aleatória em floresta tropical úmida de terra firme na região de Manaus. Acta Amazônica, Manaus, v. 16/17, n. único, p. 393-400, 1987.

ICMBio. A floresta nacional do Tapajós, 2018. Disponível em:<http://www.icmbio.gov.br/flonatapajos/>. Acesso em: 08 Jul. 2018.

SILVA, J. N. M.; DE CARVALHO, J. O. P.; LOPES, J. Inventário florestal de uma área experimental na Floresta Nacional do Tapajós. Boletim de Pesquisa Florestal, Colombo, n. 10-11, p. 38-110, 1985.

SILVA, J.N.M. 2001. Manejo Florestal. Embrapa Amazônia Oriental, $3^{a}$. ed. Belém.49p. 
SNIF - SISTEMA NACIONAL DE INFORMAÇÕES FLORESTAIS. Estoque das Florestas. Serviço Florestal Brasileiro, 2018. Disponível em http://www.florestal.gov.br/snif/recursos-florestais/estoque-das-

florestas?print=1\&tmpl=component. Acesso em 10 jul. 2018.

SOARES, C. P. B.; PAULA NETO, F.; SOUZA, A. L. Dendrometria e inventário florestal. Viçosa, MG: Universidade Federal de Viçosa, 2006. 276p 